\title{
Endoscopic localization of colorectal cancer: Study of its accuracy and possible error factors
}

\author{
Fernando Borda, Francisco Javier Jiménez, Ana Borda, Jesús Urman, Silvia Goñi, Miriam Ostiz \\ and José Manuel Zozaya \\ Department of Gastroenterology. Complejo Hospitalario de Navarra (A). Pamplona, Navarra. Spain
}

\begin{abstract}
Introduction: accurate preoperative localization of colorectal cancer $(\mathrm{CRC})$ is very important, with a wide range of published error rates.

Aims: to determine accuracy of endoscopic localization of CRC in comparison with preoperative computed tomography (CT). To analyse variables that could be associated with a wrong endoscopic localization.

Patients and methods: endoscopic and CT localization of a series of $\mathrm{CRC}$ without previous surgery were reviewed. We studied the concordance between endoscopic and radiologic localization against operative findings comparing accuracy of endoscopy and $\mathrm{CT}$. We analysed the frequency of wrong endoscopic diagnoses with regard to a series of patient, endoscopy and tumor variables.

Results: two hundred thirty seven CRC in 223 patients were studied. Concordance with surgical localization was: colonoscopy $=0.87$ and $\mathrm{CT}=0.69$. Endoscopic localization accuracy was: 91.1\%; CT: 76.2\%: $\mathrm{p}=0.00001 ; \mathrm{OR}=3.22$ (1.82-5.72). Obstructive cancer presented a higher rate of wrong localization: $18 \mathrm{vs}$. $5.7 \%$ in non-obstructive tumors $(\mathrm{p}=0.0034$; OR $=3.65(1.35$ 9.96). Endoscopic localization mistakes varied depending on tumor location, being more frequent in descending colon: $36.3 \%, p=$ $0.014 ;$ OR $=6.23(1.38-26.87)$ and cecum: $23.1 \%, p=0.007$; $\mathrm{OR}=3.92(1.20-12.43)$

Conclusions: endoscopic accuracy for CRC localization was very high and significantly better than $\mathrm{CT}$ accuracy. Obstructive tumor and those located in the descending colon or cecum were associated with a significant increase of the error risk of CRC endoscopic localization.
\end{abstract}

Key words: Colorectal cancer. Endoscopic localization. CT localization. Error factors.

Borda F, Jiménez FJ, Borda A, Urman J, Goñi S, Ostiz M, Zozaya JM. Endoscopic localization of colorectal cancer: Study of its accuracy and possible error factors. Rev Esp Enferm Dig 2012; 104:512-517.

Received: $31-05-2012$

Accepted: 28-08-2012

Correspondence: Fernando Borda. Department of Gastroenterology. Complejo Hospitalario de Navarra (A). C/ Irunlarrea, 3. 31008 Pamplona. Navarra, Spain e-mail: bordafernando@yahoo.es

\section{INTRODUCTION}

At present, colonoscopy is still considered the "gold standard" for the diagnosis of colorectal cancer (CRC) and to determine the anatomical colonic segment where the lesion is located (1-4). Once CRC has been diagnosed, computed tomography (CT) performance is indicated in the preoperative staging. CT findings allow not only tumor staging but also tumor localization in the colon (5-8).

Accurate CRC preoperative localization is very important in order to indicate adequate surgical treatment. This fact is even more relevant under certain circumstances, as in cases of endoscopically resected malignant polyps which require further surgery, small or flat tumors and neoplasms located close to the splenic flexure, all of them difficult cases for surgical localization of the lesion (9). Finally, the spread of laparoscopic surgery in the treatment of CRC, with obvious advantages $(1,10)$ has the disadvantage of loosing the opportunity of intraoperative colonic palpation, which can lead to the impossibility of identifying the tumor if we don't previously know its accurate location (11).

According to the literature, endoscopic accuracy for a correct localization of CRC shows controversial results, with a range of a wrong localization between 4 and $34 \%$ $(1,2,5,9,12-17)$. Besides this wide range regarding wrong endoscopic localization, it is remarkable the lack of papers analysing possible factors which can lead to a mistaken localization (9). It is also notorious the lack of agreement concerning the anatomic colonic segments where errors are more frequent $(12,14,15,18)$.

For these reasons we designed this study with a double aim: first to determine our endoscopic accuracy in the localization of CRC, comparing the results with those of preoperative CT. Second, to analyse possible variables of the patient, tumor or colonoscopy, which could be related to a higher risk of an erroneous endoscopic localization to the tumor. 


\section{PATIENTS AND METHODS}

A retrospective longitudinal and observational study was performed in a series of consecutive colorectal cancers diagnosed by means of colonoscopy plus biopsy and confirmed by the study of the surgical specimen from January $1^{\text {st }} 2008$ to December $31^{\text {st }} 2010$. The study was approved by the Hospital Management to allow records review.

Inclusion criteria were CRC diagnosed de novo without previous history of colonic resective surgery and with a preoperative abdominal CT. Patients who did not undergo surgery and patients with a colonoscopy report signed by more than one endoscopist, were excluded.

The "gold standard" for tumor localization was that obtained at the time of surgery, which was divided into rectum, sigmoid colon, descending colon, transverse colon, ascending colon and cecum.

Preoperative CT was performed after colonoscopy. Therefore the endoscopist was the only blind explorer regarding CRC location, as both the radiologist and surgeon were aware of the possible tumor location. This study did not assess the accuracy of barium enema as the procedure was only performed in five patients with obstructive tumors.

In our center the endoscopic identification of the different colonic segments is established according to the following features -cecum: Segment limited by the ileocecal valve which includes the appendiceal orifice; ascending colon: Between the ileocecal valve and the shadow of the hepatic flexure; transverse colon: Between the shadows of the hepatic and splenic flexures, with a triangular shape of its haustras; descending colon: Straight segment between the splenic flexure and $40 \mathrm{~cm}$ (while withdrawing the endoscope); sigmoid colon: Tortuous segment between 40 and $15 \mathrm{~cm}$ from the anus; rectum: The distal $15 \mathrm{~cm}$.

Concordance between surgical location and radiologic and endoscopic localization was studied based on CT and colonoscopy reports. We compared endoscopic localization accuracy with that of CT: We determined the possible variation of endoscopic accuracy along the 3 years of the study period.

To assess those parameters which could be associated to a wrong tumor localization, we compared the frequency of erroneous endoscopic diagnoses with regard to the following variables: sex; age $>70 \mathrm{yr}$; body mass index divides into $<20$ (low weight), 20-24 (normal weight), 25-29 (overweight) and $\geq 29$ (obesity); colon cleansing: good (proper visualization of the mucosa), fair (liquid content which allows an acceptable examination of the mucosa) an poor (solid or liquid content which makes difficult mucosa examination); endoscopist expertise (staff $v s$. last year resident); presence of synchronous cancer; colonic obstruction and finally anatomical colonic location for CRC in the different segments of the colon.

Statistical analysis was performed with SPSS-17 programme, using Kappa, Fisher and Square Chi tests and determining odds ratio (OR) and $95 \%$ confidence interval (CI 95\%). We considered significant values of $\mathrm{p}<0.05$.

\section{RESULTS}

Two hundred and thirty seven CRC in 223 patients were analysed. We registered an isolated tumor in 210 cases, double in 12 and in one patient 3 synchronous neoplasms were diagnosed. Median age was $69.5 \pm 11.2$ years.

Colonoscopies were performed by 14 specialists: 11 staff doctors and 3 last year residents. Overall characteristics are shown in table I.

In table II, anatomical CRC localization is summarized divided into surgical, endoscopic and radiologic diagnosis (CT).

Endoscopic tumor location was accurate in 216/237 cases $=91.1 \%$, CI 95\%: (87.3-95) and did not vary along the study period: $2008=89.2 \% ; 2009=90.7 \%$ and $2010=$ 93.7\% $(\mathrm{p}=0.59)$.

Colonoscopy misdiagnosed CRC in a segment, immediately proximal to the correct location in 10 cases: $(4.2 \%)$ and immediately distal in $11(4.6 \%)$. In two patients $(0.9 \%)$ inaccurate endoscopic location led to an intraoperative colonoscopy and in one case scheduled laparoscopic surgery became open surgery.

All CT were performed and reported by two expertise radiologists, according to the guidelines and criteria provided by their department.

CRC was correctly located by CT in 181/237 neoplasms, which means an accuracy of $76.3 \%$; CI 95\%: (70.8-82). The radiological exploration was unable to

Table I. Characteristics of the study group

\begin{tabular}{|c|c|c|}
\hline Parameters & $n$ & $\%$ \\
\hline \multicolumn{3}{|l|}{ Gender } \\
\hline Male & 154 & 65 \\
\hline Female & 83 & 35 \\
\hline \multicolumn{3}{|l|}{ Age } \\
\hline$<70$ years & 109 & 46 \\
\hline$\geq 70$ years & 128 & 54 \\
\hline \multicolumn{3}{|l|}{ Body mass index } \\
\hline$<20$ & 7 & 3.1 \\
\hline $20-24$ & 38 & 17.1 \\
\hline $25-29$ & 120 & 53.8 \\
\hline$>29$ & 58 & 26 \\
\hline \multicolumn{3}{|l|}{ Colon cleasing } \\
\hline Good & 164 & 70 \\
\hline Fair & 46 & 19.5 \\
\hline Bad & 25 & 10.5 \\
\hline \multicolumn{3}{|l|}{ Endoscopist expertise } \\
\hline Staff & 177 & 74.7 \\
\hline Last year resident & 60 & 25.3 \\
\hline \multicolumn{3}{|l|}{ Obstructive tumor } \\
\hline Yes & 61 & 25.7 \\
\hline No & 176 & 74.3 \\
\hline \multicolumn{3}{|l|}{ Surgery } \\
\hline Open & 164 & 69.2 \\
\hline Laparoscopic & 73 & 30.8 \\
\hline
\end{tabular}


Table II. Anatomic CRC localization, according to surgical, endoscopic or radiologic findings (TC)

\begin{tabular}{llll}
\hline Localization & $\begin{array}{l}\text { Surgery } \\
n(\%)\end{array}$ & $\begin{array}{l}\text { Endoscopy } \\
n(\%)\end{array}$ & $\begin{array}{l}C T \\
n(\%)\end{array}$ \\
\hline Rectum & $95(40.1)$ & $89(37.6)$ & $75(31.6)$ \\
Sigmoid colon & $61(25.7)$ & $68(28.7)$ & $61(25.7)$ \\
$\begin{array}{l}\text { Descending } \\
\text { Transverse }\end{array}$ & $11(4.6)$ & $11(4.6)$ & $9(3.8)$ \\
$\begin{array}{l}\text { Ascending } \\
\text { Cecum }\end{array}$ & $11(4.6)$ & $12(5.1)$ & $8(3.4)$ \\
$\begin{array}{l}\text { Not localizated or not } \\
\text { detected }\end{array}$ & $33(13.9)$ & $37(15.6)$ & $31(13.8)$ \\
\hline
\end{tabular}

$\mathrm{n}=$ number of cases; $\%=$ percentage of all the group .

locate precisely the tumor in 3 cases (1.3\%). In 28 cases $(11.8 \%)$ the tumor was not found in CT, being 6 cases malignant polyps and 7 synchronous neoplasms. An incorrect diagnosis by CT was made in 25/237 CRC (10.5\%). The erroneous radiological location situated these lesions in a segment immediately proximal to the correct location in 12 tumors $(5.1 \%)$ and immediately distal in 14 (5.9\%). Table III summarize the erroneous location of CRC by endoscopy and CT.

The accuracy registered was significantly higher when comparing the precision of tumor localization between colonoscopy and CT: $\mathrm{p}=0.00001 ; \mathrm{OR}=3.22$; CI 95\%: (1.82-5.72).

Kappa test showed a concordance between surgical and endoscopic findings of 0.87 , falling to 0.69 when comparing to $\mathrm{CT}$ results.

Among all the parameters analysed, possibly related to the erroneous tumoral location, inaccurate endoscopic location was more frequent in cases of obstructive cancer (11/61 vs. $10 / 176 ; \mathrm{p}=0.0034 ; \mathrm{OR}=3.65$ (1.35-9.96). Regarding tumor location, misdiagnosis rates were higher in descending colon: Error $=4 / 11(36.3 \%), p=0.014 ; \mathrm{OR}=6.23$; CI 95\%: $(1.38-26.87)$ and cecum: Error $=6 / 26(23.1)$,

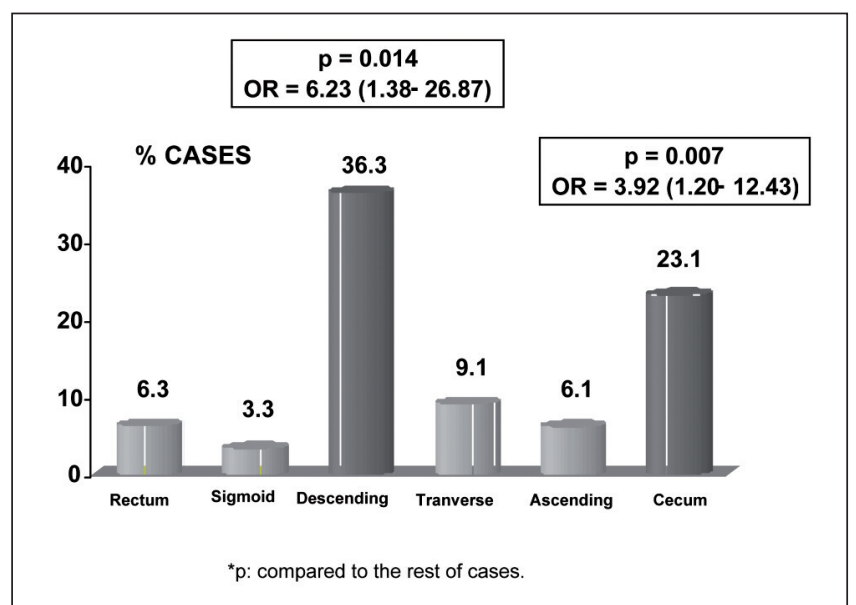

Fig. 1. Frequency of erroneous endoscopic localization, according to the segment where the $C R C$ is situated.

$p=0,007 ;$ OR $=3.92 ;$ CI 95\%: $(1.20-12.43)$. The rest of anatomical locations did not show significant differences. Rectum: Error $=6 / 95$ (6.3\%); sigmoid colon: Error $=2 / 61$ $(3.3 \%)$; transverse colon: Error $=1 / 11(9.1 \%)$; ascending colon: Error = 2/33 (6.1\%) (Fig. 1).

There were no significant differences in any of the rest of studied parameters related to the frequency of incorrect CRC location, as shown in table IV.

\section{DISCUSSION}

Surgeon previous knowledge of the accurate location of $\mathrm{CRC}$ is relevant as the lack of this information may lead to negative consequences in the surgical performance (1820 ). The need of an accurate preoperative localization of the tumor has brought the development of different endoscopic techniques in order to facilitate further tumor identification at the time of surgery, including the use of clips (21-23) and peritumoral submucosal tattooing $(1,22,24-$ 26). More recently, the use of new technologies as the

Table III. Cases of erroneous endoscopic tumor localization

\begin{tabular}{lll}
\hline Correct localization & $\begin{array}{l}\text { Endoscopic error } \\
n(\%) \text { Type of error }\end{array}$ & $\begin{array}{l}\text { CT error } \\
n(\%) \text { Type of error }\end{array}$ \\
\hline Rectum & $6(6.3)$ located in sigmoid colon & $11(11.6)$ located in sigmoid colon \\
\hline Sigmoid colon & $2(3.3)$ located in descending & $1(1.6)$ located in descending \\
\hline Descending & $3(27.3)$ located in sigmoid colon & $2(18.2)$ located in sigmoid colon \\
\hline Transverse & $1(9.1)$ located in transverse & $1(9.1)$ located in descending \\
\hline Ascending & $1(9.1)$ located in descending & $4(12.1)$ located in cecum \\
\hline Cecum & $1(3)$ located in transverse & $6(23.2)$ located in ascending \\
\hline Not localizated or not detected & $1(3)$ located in cecum & $31(13.1)$
\end{tabular}


"scope guide" or "magnetic endoscopic imaging" has been proposed in order to identify the position of the endoscope in the colon $(5,21,27)$, therefore facilitating detected lesions location.

Besides endoscopy, other procedures can help in the localization of CRC. The main indication of preoperative colonography are those cases of incomplete colonoscopy due to the presence of an obstructive tumor allowing the examination of colonic segments proximal to the structure, but it has also showed excellent results for the localization of CRC $(1,6,19,25)$.

Finally, if the surgeon has difficulties in identifying the lesion, both intraoperative hydrocolonic ultrasonography and intraoperative colonoscopy $(1,25)$ can be performed, although secondary colonic distension can interfere with laparoscopic surgery performance (29).

Regarding endoscopic localization, every published paper shows a certain percentage of wrong preoperative tumor localization $(1,2,5,9,12-17)$. As we have already mentioned, it is remarkable the variability of reported rates of mistaken localization, ranging between $4 \%$ (14) and 34\% (17). This last study was published in 1988 and its bad results could be related to the use of less sophisticated endoscopic material. However, more recent publications still report high rates of erroneous endoscopic localization: $21 \%$ in 2005 (9) and 20.2\% in 2010. Our percentage of mistaken localization, $8.9 \%$, did not show relevant variation during the study period and is only worse than the $4 \%$ of Vaziri in 2010 (14) and the $6.25 \%$ of Ellul in 2011, in this case using an electromagnetic system to make a $3 \mathrm{D}$ estimation of the intracolonic position of the endoscope (5).

The consequences for the patient with erroneous preoperative tumor localization can be multiple. Complication include inadequate patient positioning for surgical intervention (2), wrong situation of laparoscopic port (9), the need of exploratory manoeuvres during surgery increasing duration and cost of the procedure (2). Erroneous tumor localization can have more consequences, causing in 4$12 \%$ of cases a change of planned surgical strategy, including reconversion of laparoscopic to open surgery $(9,19)$. Under certain circumstances, an error will not influence the surgical procedure (right hemicolectomy with a wrong diagnosis between cecum or ascending colon). However several publications have showed that a previous mistaken localization has been responsible of serious situations as resecting a colonic segment not containing the tumor $(2,18,20)$. In all our cases, errors consisted in localizing CRC in the proximal or distal segment to its real surgical situation, and so initial surgical plan had to be modified in only one case, changing to open surgery and intraoperative colonoscopy performance was required in two patients.

The main indication of preoperative CT in colorectal cancer is tumor staging, being less useful for tumor diagnosis and localization $(7,8)$ and with higher accuracy rate than other radiologic procedures as colonography $(1,6,19)$. Quite often, CT can not identify the tumor, particularly with
Table IV. Parameters without statistical significance, regarding erroneous tumor localization

\begin{tabular}{lll}
\hline Parameters & Incorrect localization (\%) & $n$ \\
\hline Gender & & 0.86 \\
Male & 9.1 & \\
Female & 8.4 & 0.28 \\
Age & & \\
$<70$ years & 11 & \\
$\geq 70$ years & 9.3 & 0.59 \\
Body mass index & & \\
$<20$ & 12.5 & \\
$20-24$ & 13.1 & \\
$25-29$ & 8.4 & 0.95 \\
$>29$ & 7 & \\
Colon cleasing & & \\
Good & 9.2 & 0.79 \\
Fair & 8.9 & \\
Bad & 8.6 & 0.98 \\
Endoscopist expertise & 8.6 & \\
Staff & 10 & \\
Last year resident & 10.7 & \\
Synchronous cancer & 8.6 & \\
Yes & & \\
No & & \\
\hline
\end{tabular}

small lesions with published misdiagnosis rates of $32.7 \%$ (2). This lack of tumor identification occurred in $11.8 \%$ of our patients, being malignant polyps or synchronous tumors of small size in half of the cases. Our overall CT accuracy for a correct tumor localization, $76.3 \%$, is situated in the middle of other published series, ranging from 50 to $83 \%$ $(2,5)$. As in other reports, CT accuracy has been lower than colonoscopy precision, reaching statistical significance and presenting a three fold risk of erroneous localization. In agreement with these data, CRC localization concordance between CT and surgery, assessed with Kappa test, could only be considered important while it was almost perfect between surgery and colonoscopy. Finally we would like to comment that surgical decisions were taken according to endoscopic findings and so CT errors had no influence on patients management. Among published papers, only the publication of Piscatelli (9), statistically analyses possible error causes. The authors conclude that only previous colorectal resective surgery was significantly related to a higher rate of incorrect tumor localization. It seems obvious that previous surgery modify certain anatomic references useful for the endoscopist, facilitating a mistake in lesions location. For this reason we considered previous colonic surgery as an exclusion criterion in our series and perhaps this could influence the good obtained results.

In agreement with Piscatelli (9), sex, age or colonic cleansing had no relation with the frequency of errors in CRC localization.

It has been proposed the influence of the endoscopist in tumor localization (1). This possibility is more remarkable 
in other countries where endoscopy is performed by different medical specialist: gastroenterologists, surgeons and even internal medicine and general physicians (9). We compared accuracy of tumor localization between staff doctors and residents. The 11 staff doctors who performed colonoscopies had wide expertise in diagnostic and therapeutic endoscopy. The 3 trainees were last year residents who, under supervision, performed and reported endoscopic procedures. In our study, as expected, errors were less frequent for staff doctors (8.6\%) than for residents $(10 \%)$, although as in previous published series (9) statistical significance was not reached.

Obstructive tumors, with impossible colonoscope passage, were associated with significant increase of wrong localization, with a three fold error risk. Even though without statistical assessment, a Korean study mentioned the high rate of erroneous endoscopic localization in cases of obstructive tumors (19). A possible explanation could be that in an incomplete colonoscopy certain anatomic references are not reached, as colonic flexures and ileocecal valve, making accurate localization more difficult (19).

We have studied the possible relation between the colonic segment where the tumor is located and the risk of erroneous endoscopic location. In our series, CRC localization in the cecum and descending colon was associated with a significant higher rate of wrong diagnosis, presenting a sixfold and four-fold error risk respectively.

The scant available literature shows controversial results regarding the distribution of endoscopic errors among the different colonic anatomical segments. Some authors agree with us indicating a high rate of wrong localization in the left colon (15), both in the descending and the sigmoid colon (14). In the majority of cases, inadequate localization is favoured by the variable length and mobility of the sigmoid colon as well as by the lack of anatomical and endoscopical marks to define the transition between the sigmoid and descending colon. Surprisingly, other paper report completely opposite data, no finding endoscopic errors when the tumors are located in the descending (18) or the sigmoid colon (2). Finally, the comment that, as in our series, a high number of endoscopic errors has been reported for cecal CRC (12). In this anatomical segment, tumors can be large and make difficult ileocecal valve visualization. This fact can lead the endoscopist to localize the tumor in the ascending colon instead of the cecum.

With the limitation of any retrospective study, and a possible bias in the reported results, we conclude that: colonoscopy accuracy for a correct CRC localization has been very high, better than the majority of previously published series, and significantly higher than that of preoperative abdominal CT. Concordance between surgical and endoscopic tumor localization has been excellent. Among all the assessed parameters, obstructive tumors, and tumors located in the cecum or descending colon are associated with a significant increase of the error risk in the endoscopic localization of CRC.

\section{REFERENCES}

1. Cho YB, Lee WY, Yun HR, Lee WS, Yun SH, Chun HK. Tumor localization for laparoscopic colorectal surgery. World J Surg 2007;31:14915 .

2. Lee J, Voytovich A, Pennoyer W, Thurston K, Kozol RA. Accuracy of colon tumor localization: computed tomography scanning as a complement to colonoscopy. World J Gastrointest Surg 2010;2:22-5.

3. Morán S, Torrella E, Esteban P, Baños R, Garcia A, Ono A, et al. Colonoscopy quality assessment. Rev Esp Enferm Dig 2009;101:107-12.

4. Vallverdú H, Comajuncosas J, Orbeal RA, López J1, Gris PJ, Garriga PJ, et al. Results of implementation of a fast track pathway for diagnosis of colorectal cancer. Rev Esp Enferm Dig 2011;103:402-7.

5. Ellul P, Fogden E, Simpson C, Buhagiar A, McKaig B, Swarbrick E, et al. Colonic tumour localization using an endoscope positioning device. Correlation between preoperative endoscopic and intraoperative findings in localizing colorectal lesions. Eur J Gastroenterol Hepatol 2011;23:488-91.

6. Neri E, Turini F, Cerri F, Faggioni L, Vagli P, Naldini G, et al. Comparison of CT colonography vs. Conventional colonoscopy in mapping the segmental location of colon cancer before surgery. Abdom Imaging 2010;35:589-95.

7. Mauchley DC, Linge DC, Langdale LA; Stelzner MG, Mock CN, Billingsley KG, et al. Clinical utility and cost-effectiveness of routine preoperative computed tomography scanning in patients with colon cancer. Am J Surg 2005;189:512-7.

8. Barton JB, Langdale LA, Cummins JS, Stelzner MG, Linge DC, Mock $\mathrm{CN}$, et al. The utility of routine preoperative computed tomography scanning in the management of veterans with colon cancer. Am J Surg 2002;183:499-503.

9. Piscatelli N, Hyman N, Osler T. Localizing colorectal cancer by colonoscopy. Arch Surg 2005;140:932-5.

10. Clinical Outcomes of Surgical Therapy Study Group. A comparison of laparoscopically assisted and open colectomy for colon cancer. N Engl J Med 2004;350:2050-9.

11. Holzman MD, Eubanks S. Laparoscopic colectomy: prospects and problems. Gastrointest Endosc Cin N Am 1997;7:525-39.

12. Vignati P, Welch JP, Cohen JL. Endoscopic localization of colon cancers. Surg Endosc 1994;8:1085-7.

13. Stanciu C, Trifan A, Khder SA. Accuracy of colonoscopy in localizing colonic cancer. Rev Med Chir Soc Med Nat Iasi 2007;111:39-43.

14. Vaziri K, Choxi SC, Orkin BA. Accuracy of colonoscopic localization. Surg Endosc 2010;24:2502-5.

15. Louis MA, Nandipati K, Astorga R, Mandava A, Rousseau CP, Mandava N. Correlation between preoperative endoscopic and intraoperative findings in localizing colorectal lesions. World J Surg 2010;34:158791.

16. Lam DT, Kwong KH, Lam CW, Leong HT, Kwok SP. How useful is colonoscopic in locating colorectal lesions? Surg Endosc 1998;12:83941.

17. Tabibian N, Michaletz PA, Schwartz JT, Heiser MC, Dixon WB, Smith JL, et al. Use of an endoscopically placed clip can avoid diagnostic errors in colonoscopy. Gastrointest Endosc 1988;34:262-4.

18. Frager DH, Frager JD, Wolf EL, Beneventano TC. Problems in the colonoscopic localization of tumors: continued value of the barium enema. Gastrointest Radiol 1987;12:343-6.

19. Kim JH, Kim WH, Kim TL, Kim NK, Lee KY, Kim MJ, et al. Incomplete colonoscopy in patients with occlusive colorectal cancer: usefulness of CT colonography according to tumor location. Yonsei Med J 2007;48:934-41.

20. Wexner SD, Cohen SM, Ulrich A, Reissman P. Laparoscopic colorectal surgery: are we being honest with our patients? Dis Colon Rectum 1995;38:723-7.

21. Ambardar S, Amell TD, Whelan RL, Nihalani A, Forde KA. A preliminary prospective study of the usefulness of a magnetic endoscope locating device during colonoscopy. Surg Endosc 2005;19:897-901.

22. Ellis KK, Fennerty MB. Marking and identifying colon lesions. Tattoos, clips and radiology in imaging the colon. Gastrointest Endosc Cin N Am 1997;7:401-11.

23. Ohdaira T, Konishi F, Nagai H, Kashiwagi H, Shito K, Togashi K, et al. Intraoperative localization of colorectal tumors in the early stages using a marking clip detector system. Dis Colon Rectum 1999; 42:1353-5. 
24. Conaghan PJ, Maxwell-Armstrong CA, Garrioch MV, Hong L, Acheson AG. Leaving a mark: The frequency and accuracy of tattoing prior to laparoscopic colorectal surgery. Colorectal Dis 2011;13:11847.

25. Yeung JM, Maxwell-Armstrong CA, Acheson AG. Colonic tattoing in laparoscopic surgery. Making the mark? Colorectal Dis 2009;11:527-30.

26. Askin MP, Waye JD, Fiedler L, Harpaz N. Tattoo of colonic neoplasms in 113 patients with a new sterile carbon compound. Gastrointest Endosc 2002;56:339-42.
27. Jees $\mathrm{P}$, Bulut $\mathrm{O}$, Almasi A, Waaddegaard $\mathrm{P}$. The usefulness of a magnetic endoscope locating device in colonoscopy in daily practice: a prospective case-controlled study. Surg Endosc 2009;23:1353-5.

28. Greif F, Aranovich D, Zilbermints V, Hannanel N, Belenky A. Intraoperative hydrocolonic ultrasonography for localization of small colorectal tumors in laparoscopic surgery. Surg Endosc 2010;24:3144-8.

29. Kim SH, Milsom JW, Church JM, Ludwig KA, García-Ruiz A, Okuda J. et al. Perioperative tumor localization for laparoscopic colorectal surgery. Surg Endosc 1997;11:1013-6. 